\title{
1 Genome size drives morphological evolution in organ-specific ways
}

3 Michael W. Itgen ${ }^{1}$, Dustin S. Siegel ${ }^{2}$, Stanley K. Sessions ${ }^{3}$, Rachel Lockridge Mueller ${ }^{1}$

4 1. Department of Biology, Colorado State University, Fort Collins, CO 80523, USA

5 2. Department of Biology, Southeast Missouri State University, Cape Girardeau, MO

$6 \quad 63701$, USA

7 3. Biology Department, Hartwick College, Oneonta, NY 13820, USA

8 Corresponding author: Itgenm@ colostate.edu 


\section{Abstract}

11 Morphogenesis is an emergent property of biochemical and cellular interactions during

12 development. Genome size and the correlated trait of cell size can influence these interactions

13 through its effects on developmental rate and tissue geometry, ultimately driving the evolution of

14 morphology. We tested the effects of genome size and body size evolution on heart and liver

15 morphology using nine species of the salamander genus Plethodon (genome sizes 29.3-67 Gb).

16 Our results show that whole organ size is determined by body size, whereas tissue structure

17 changes dramatically with evolutionary increases in genome size. In the heart, increased genome

18 size is correlated with a reduction of myocardia in the ventricle, yielding proportionally less

19 force-producing mass and more empty space. In the liver, increased genome size is correlated

20 with fewer and larger vascular structures, positioning hepatocytes farther from the circulatory

21 vessels that transport key metabolites. Although these structural changes should have obvious

22 impacts on organ function, their effects on organismal performance and fitness are likely

23 negligible because low metabolic rates in salamanders relax selective pressure on key metabolic

24 organ performance. Overall, this study reveals the effects of large genome and cell size on the

25 developmental systems producing the heart and liver.

27 Keywords: Comparative methods, Evolutionary development, Cell size, Histology, MicroCT,

28 Salamanders.

\section{Introduction}

32 possible phenotypes for a species and selection to match these phenotypes to the environment. 
33 While optimal trait values theoretically exist for any species in any environment, in reality, there

34 are evolutionary constraints that define a limited set of possible phenotypes from all theoretical

35 ones across morphospace (Alberch, 1982). Evolutionary constraints can exist at all levels of

36 biology and can involve both developmental and physical limitations that can introduce bias or

37 prevent certain phenotypes from evolving (Maynard Smith et al., 1985; Arnold, 1992;

38 Brakefield, 2006; Gerber, 2014).

The separation of possible from theoretical phenotypes in morphospace is often defined

40 by whether the phenotypes can be produced by the species' developmental system (Alberch,

41 1982; Salazar-Ciudad, 2006). The process of development is an emergent property of

42 biochemical and cellular interactions that direct morphogenesis. Gene expression and signal

43 transduction networks instruct populations of cells to divide, differentiate, migrate, and coalesce

44 (Alberch, 1982; Oster et al., 1988). In addition, cells influence their neighbors, relaying

45 positional and deterministic information to one another that results in the induction of tissue

46 formation and organogenesis. Molecular- and cell-level processes are both required; genes and

47 gene products alone cannot produce tissues and organs without the organizational level of cells,

48 and cells cannot organize without molecular instruction. When genes, proteins, or cells evolve

49 within this system, any new variant can potentially alter these collective interactions and change

50 the outcome of development.

Alberch (1982) proposed that the primary forces underlying the evolution of morphology

52 are changes to the biochemical and cellular interactions involved in development. Overall,

53 development is robust to change, and variation — both mutational and epigenetic — can often

54 have no impact on the resulting phenotype (Lewontin, 1972; Oster and Alberch, 1982; Wagner,

55 2011; Uller et al., 2018). Thus, many possible interactions between molecules and cells exist that 
56 will yield the same developmental outcome (Alberch, 1982; Oster and Alberch, 1982). However,

57 some such changes will result in the developmental system producing a different phenotype

58 (Oster and Alberch, 1982; Uller et al., 2018). These changes cross a theoretical threshold called a

59 bifurcation boundary, which bounds the amount of variation permittable within a developmental

60 system that still produces the same outcome (Oster and Alberch, 1982). This variation can exist

61 in many parameters, including: sequence, structure, function, and interaction of genes and

62 proteins; rates of diffusion and biochemical reactions; morphology and motility of cells; rates of

63 cellular division and differentiation; and the size and organization of tissues and structures

64 (Alberch, 1983; Brakefield et al., 2003; Mallarino et al., 2011; Keyte and Smith, 2014; Powder et

65 al, 2015). Variations in these parameters can collectively alter morphogenesis and result in larger

66 scale changes that impact the rate of development, the sequential timing of developmental

67 events, or pattern formation, pushing the system across a bifurcation boundary (Oster and

68 Alberch, 1982).

69 Genome size is a trait that can directly impact developmental systems through its effects

70 on cell biology (Gregory, 2005). There is a strong positive correlation between genome size and

71 cell size, resulting in cells becoming larger as DNA accumulates (Gregory, 2005; D'Ario et al.,

72 2021). Large cell size has clear impacts on cell morphology, shifting the ratio between surface

73 area and volume and causing the scaling of intracellular organelles (Marshall et al., 2012).

74 Genome and cell size together have been shown to impact developmental systems through two

75 mechanisms (Gregory, 2005). First, large genome and cell sizes slow developmental rate by

76 causing longer cell cycles and slower rates of cell migration and differentiation (Sessions and

77 Larson, 1987; Schmidt and Roth, 1993; Vinogradov, 1999). This slowing can ultimately shift the

78 timing of developmental events (i.e., heterochrony) and impact the dynamics of morphogenesis 
79 (Alberch et al., 1979; Gould, 1985). Changes in cell size also impact the final outcomes of

80 development: the structures of tissues and organs (Alberch and Alberch, 1981; Hanken and

81 Wake, 1993; Roth et al., 1993). Tissues and organs are a function of both cell size and cell

82 number. Therefore, evolutionary increases in genome and cell size can result in organs and

83 organisms that are composed of fewer, larger cells, assuming body size and organ size remain

84 constant (Hanken and Wake, 1993). Morphogenesis must then occur with fewer cells, and the

85 final organ or structure must be able to maintain function with fewer, larger cells. increased genome and cell size — mediated through alterations to the developmental system — can vary extensively across different organs, structures, and species (Fankhauser, 1945; Hanken and Wake, 1993; Roth et al., 1993; Snyder and Sheafor, 1999; Womack et al., 2019).

90 Amphibians, particularly salamanders, have provided a powerful system for studying these

91 patterns and processes due to their enormous range in genome and cell size (Gregory, 2005;

92 Sessions, 2008; Sessions and Wake, 2021). Much of this work has focused on the brain and

93 nervous system, the skeletal system, and the circulatory system. Within the salamander brain,

94 dramatic changes in gross morphology and tissue organization are connected to larger genome

95 and cell sizes as well as reductions in cell numbers (Roth et al., 1993; Roth and Walkowiak,

96 2015). Several brain regions including the thalamus, praetectum, and midbrain become

97 proportionally larger primarily through a reduction in the forebrain (Roth et al., 1988, 1990).

98 Larger and fewer cells also impact tissue organization, leading to an increase in gray matter

99 relative to white matter as well as increased cell density in several tissues (Roth et al., 1990). In

100 addition, slower rates of cell proliferation and migration caused by large genome and cell size

101 results in a decrease in lamination within the tectum mesencephali (Schmidt and Roth, 1993). 
Amphibian skeletal elements also show a variety of effects because of genome and cell

103 size increase (Alberch and Alberch, 1981; Hanken and Wake, 1993; Womack et al., 2019). In

104 tropical lungless salamanders with exceptionally large genomes, slower development rates

105 appear to be connected to paedomorphic morphologies including fenestrated skulls, highly

106 reduced or even absent phalangeal elements in the digits, and extensively webbed feet (Wake,

107 1966; Alberch and Alberch, 1981; Alberch, 1983; Jaekel and Wake, 2007; Decena-Segarra et al.,

108 2020). In addition, the relationship between cell size and body size — also known as biological

109 size (Hanken and Wake, 1993) — appears to disrupt skeletal development when genome size

110 increases (and/or body size decreases) because the prerequisite tissues that form the bones are

111 reduced to significantly fewer cells (Hanken, 1982, 1984; Wake, 1991). In some cases, the carpal

112 and tarsal elements of the feet remain cartilaginous and are often fused due to a failure to

113 separate during development (Wake, 1966; Alberch and Alberch, 1981). In extreme cases,

114 abnormal morphologies and losses of skeletal elements occur, often asymmetrically within single

115 individuals. The same skeletal elements can show different patterns of change accompanying

116 increased cell size depending on body size (Wake, 1991; Hanken and Wake, 1993). Comparative

117 analyses have found evidence that miniaturized salamanders have undergone genome size

118 reduction because of the consequences of limited cell number as a developmental constraint

119 (Decena-Segarra et al., 2020).

120 Large genome and cell size has also impacted the circulatory and excretory systems. Red

121 blood cell size is positively correlated with genome size across vertebrates (Gregory, 2001).

122 Evolutionary increases in red blood cell size are accompanied by wider capillary diameters

123 (Snyder and Sheafor, 1999). Multiple lineages of miniaturized salamanders have secondarily

124 evolved enucleated red blood cells to reduce cell size and permit passage through small 
125 capillaries (Villalobos et al., 1988; Mueller et al., 2008; Itgen et al., 2019; Decena-Segarra et al.,

126 2020). In contrast, experimental induction of polyploidy (and thus increased cell size) did not

127 result in proportional increases in the diameter of pronephric tubules, which are excretory

128 structures similar in morphology to capillaries; however, increased ploidy did alter the

129 morphology and number of cells comprising the structure (Fankhauser, 1945).

130 The diversity of morphological outcomes in the studies carried out to date suggests that

131 the fundamental rules governing the effects of genome and cell size on morphological evolution

132 will be revealed through the analysis of additional organs and the synthesis of results across

133 species and organ systems. As a step towards this goal, our study investigates how increases in

134 genome and cell size impact the morphology of the heart and liver. These two previously

135 unexplored organs differ in morphogenesis and function; the heart has a kinetic biomechanical

136 function and the liver has a biochemical and secretory function. Our study system is the lungless

137 salamander genus Plethodon, which includes species with dramatic differences in genome size

$138(23-67 \mathrm{~Gb})$ and cell size, but uniformity or lower diversity in potentially confounding variables

139 that could also impact organ structure and function (life history, body size; Highton, 1995;

140 Newman et al., 2016). Using diffusible iodine-based contrast-enhanced computed tomography

141 (diceCT) and histology applied to nine focal Plethodon species, we quantified body size, organ

142 size, and several measures of tissue composition and geometry: 1) proportion of the heart wall

143 comprised of cardiomyocytes versus lumen, 2) proportion of the liver comprised of hepatocytes

144 versus vascular openings, and 3) the numbers and sizes of distinct vascular structures (sinusoids,

145 veins, arteries) in the liver. We used phylogenetic comparative methods to test whether these

146 variables correlate with evolutionary changes in genome and cell size. Based on our findings, we

147 propose hypotheses connecting cell size, developmental system perturbation, and morphology. 
148 More generally, we discuss how relaxed functional constraints on organ performance can allow

149 the evolution of a range of structurally different, but functionally equivalent, morphologies.

\section{Methods}

Animal collection_-We collected five adult individuals of $P$. cinereus, $P$. cylindraceus,

152 P. dunni, P. glutinosus, P. idahoensis, P. metcalfi, P. montanus, P. vandykei, and P. vehiculum.

153 Permit IDs and locality data can be found in the supplemental data. Salamanders were collected

154 and euthanized in buffered 1\% MS-222, fixed in buffered formalin, and transferred through a

155 graded series of ethanol $(10 \%, 30 \%, 50 \%, 70 \%)$ before storage in $70 \%$ ethanol indefinitely. The

156 protocols for animal research, husbandry, and euthanasia were approved by the Institutional

157 Animal Care and Use Committee of Colorado State University (17-7189A).

158 diceCT data generation and processing — We used diffusible iodine-based contrast-

159 enhanced computed tomography (diceCT) to collect data on liver and heart volumes (Gignac et

160 al., 2016). In order to produce the diceCT scans, specimens were stained in a $1 \% \mathrm{I}_{2} \mathrm{KI}$ solution

161 for 2 days. Specimens were scanned twice using a Bruker SkyScan 1173 at the Karel F. Liem

162 Bioimaging Center, Friday Harbor Laboratories, University of Washington. Scans were set to 85

$163 \mathrm{kV}$ and $90 \mathrm{uA}$ with a $1 \mathrm{~mm}$ aluminum filter to reduce beam hardening. We first produced full

164 body scans to measure liver volumes at a resolution ranging from 14.9-17 $\mu \mathrm{m}$, depending on the

165 size of the specimens. We then produced higher resolution scans for the heart, which were

166 scanned at a resolution ranging from 7.1-9.9 $\mu \mathrm{m}$. After the specimens were scanned, the $\mathrm{I}_{2} \mathrm{KI}$

167 was rinsed out using several changes of $70 \%$ ethanol and the specimens were stored in $70 \%$

168 ethanol. All of the specimens were treated uniformly to standardize for any $\mathrm{I}_{2} \mathrm{KI}$-related artefacts

169 or tissue shrinkage that might impact the subsequent histological analyses. 
171 operating procedures including optimal x/y alignment, ring artifact reduction, beam hardening

172 correction, and a post-alignment. Data visualization and analysis were accomplished using

173 3DSlicer (Fedorov et al., 2012). Liver and heart ventricle volumes were calculated through

174 segmentation of the liver and heart from each individual.

175 Organ measurement--Snout-vent lengths were measured to the nearest $0.01 \mathrm{~mm}$ for 176 each individual using digital calipers. The hearts and livers were then dissected out from the

177 specimens and were embedded in plastic following standard protocols (Humason, 1962). Tissues

178 were sectioned at $4 \mu \mathrm{m}$ and stained with hematoxylin for 4 minutes and toluidine for 3 minutes.

179 Sections were mounted and then visualized using a compound microscope. Images used in the

180 analysis were minimally edited to remove blood cells that obstructed vascular structures or the

181 lumen of the ventricle. Five images were taken from unique slides at 20x magnification for each

182 individual and a mean value was calculated for each morphological trait per individual. Each

183 image was converted to greyscale and a thresholding method was used to collect the

184 morphometric data. ImageJ was used for all image processing and analysis (Schneider et al.,

185 2012).

Amphibian livers are primarily comprised of hepatic tissue that is permeated by the

187 circulatory system (Akiyoshi and Inoue, 2012). Liver circulatory structures consist of hepatic

188 arteries that provide oxygen, portal veins that bring nutrients and toxins to the liver, and

189 sinusoids, which are specialized capillaries where oxygen-rich blood from hepatic arteries and

190 nutrient-rich blood from portal veins mix (Elias and Bengelsdorf, 1952). Liver tissue is generally

191 arranged into many hepatic lobules that are centered by portal triads - an arrangement of hepatic

192 arteries, portal veins, and bile ducts (Elias and Bengelsdorf, 1952). The network of sinusoids 
193 gives the hepatic tissue a cord-like appearance in most vertebrate taxa, with hepatocytes forming

194 cords that are 1-2 cells thick; this morphology increases the surface area of each hepatocyte that

195 is in contact with circulating blood (Elias and Bengelsdorf, 1952). However, some species of

196 salamanders have a many-cell thick arrangement of hepatic cords (Akioyshi and Inoue, 2012).

197 For the liver, we measured the total area of each histological section that was comprised of tissue

198 (primarily hepatocytes) versus vascular openings and the number and size of distinct vascular

199 structures (sinusoids, veins, arteries) (Fig. S1). Twenty nuclei and cells were also measured for

200 each individual to collect data on hepatocyte nuclear and cell area.

201 Amphibians have a single, thin-walled ventricle that has a central chamber surrounded by

202 a highly trabeculated network of myocardium, which is a characteristic of ectotherms

203 (Stephenson et al., 2017). Heart morphology in Plethodon also reflects the lack of lungs in the

204 family Plethodontidae, which has been accompanied by a loss of complete atrial septation (Lewis

205 and Hanken, 2017). For the heart ventricles, we measured the amount of myocardial area in the

206 ventricle walls versus lumen (Fig. S1). We focused on this because the trabeculated myocardium

207 makes it difficult to define the edges of the ventricle chamber. We did not measure any

208 characteristics of the atria because they lack distinct internal structure and their elastic nature

209 made accurate volumetric measurements impossible.

210 Genome size measurement_-Genome size was measured using the Feulgen-staining

211 method on fixed erythrocytes following the protocol of Sessions and Larson (1987). Ambystoma

212 mexicanum $(32 \mathrm{~Gb})$ was used as a standard to calculate the genome sizes of the other species.

213 The A. mexicanum were acquired from the Ambystoma Genetic Stock Center at the University of

214 Kentucky. Erythrocytes were extracted from the Plethodon and Ambystoma specimens fixed in

215 buffered formalin and transferred to microscope slides to produce blood smears. We collected 
216 blood smears from 3-5 individuals per species. The cells were hydrated for 3 minutes in distilled

217 water, permeabilized in $5 \mathrm{~N} \mathrm{HCl}$ for 20 minutes at $20^{\circ} \mathrm{C}$, and then rinsed three times in distilled

218 water. Nuclei were stained with Schiff's reagent for 90 minutes at $20^{\circ} \mathrm{C}$, destained in $0.5 \%$

219 sodium metabisulfite three times for 5 minutes each, and then rinsed in distilled water three

220 times. The stained cells were dehydrated in a graded series of 70\%, 95\%, and 100\% ethanol,

221 dried, and mounted. We photographed 2-12 (x $\square=5.5)$ nuclei per individual under 100x, and the

222 integrated optic densities (IOD) were measured using IMAGE PRO software (Media

223 Cybernetics, Rockville, Maryland, USA). Genome sizes were calculated by comparing the

224 average IODs of the experimental species to the IOD of the standard. Nuclear areas were also

225 measured for each erythrocyte using the IMAGE PRO software.

226 Phylogeny_ We estimated the phylogenetic relationships among the 9 species of

227 Plethodon used in this study to account for phylogenetic non-independence in our analyses.

228 DNA sequences for the mtDNA gene $c y t b$ and the nuclear gene Rag 1 were obtained from NCBI

229 (https://www.ncbi.nlm.nih.gov/genbank; Table S1). The cytb and Ragl datasets were aligned

230 independently using MUSCLE in MEGA v7 with default parameters and trimmed to 629 and

231 1,467 basepairs, respectively (Edgar, 2004; Kumar et al., 2016). We selected a GTR+G+I

232 nucleotide substitution model by running PartitionFinder 2 on each codon position for both genes

233 (Lanfear et al., 2017). The phylogeny was estimated using Bayesian inference with MrBayes

234 v3.2.5 (Ronquist et al., 2012). The analysis ran with four chains (3 heated, 1 cold) for 10 million

235 generations with sampling occurring every 1,000 and the first $10 \%$ of the sampled trees

236 discarded as burnin.

237 Data analysis_— We first tested if organ morphological traits, genome size, and SVL

238 were phylogenetically dependent by estimating phylogenetic signal using Blomberg's K based 
on our midpoint-rooted phylogeny. Blomberg's K was calculated using the phytools package

240 implemented in R v 3.4.2 (Revell, 2012; R core team, 2016). We then log-transformed all

241 variables to account for non-normal distributions and calculated phylogenetic independent

242 contrasts (PICs) for each variable using the R package phytools (Revell, 2012). We ran a

243 MANOVA and subsequent post-hoc univariate ANOVA analysis on a model including SVL and

244 genome size as predictor variables and all morphological data as response variables to test if

245 organ morphology is correlated with genome size and/or SVL while accounting for phylogeny.

246 Our response variables included liver size, ventricle size, total area comprised of muscle in the

247 ventricle, number of vascular structures in the liver, average size of the vascular structures in the

248 liver, and the total area comprised of hepatic tissues in the liver. The MANOVA and univariate

249 ANOVA analyses were conducted using R v 3.4.2 ( $\mathrm{R}$ core team, 2016).

250 We applied a Brownian motion model of evolution to all variables because there is

251 evidence that genome size evolves by largely stochastic processes in direct-developing

252 salamanders such as Plethodon (Mueller et al., preprint). Because we hypothesize that organ

253 morphology is shaped by the evolution of genome and cell size, we predict that the heart and

254 liver morphological traits are not evolving towards adaptive optima. We visualized the

255 magnitude and direction of changes in genome size across the 9 species of Plethodon in the study

256 using the contMap function in the R package phytools on the estimated topology (Revell, 2012).

Results

The genome size estimates for the 9 Plethodon species ranged from 29.3-67.0 Gb (Figure

259 1; Table 1). The genome sizes estimated in this study were generally larger than those previously

260 published or fell within the higher range of published estimates (Gregory, 2021). We estimated

261 larger genome sizes for P. cinereus (29.3 Gb vs. $25.6 \mathrm{~Gb}), P$. dunni (52.3 Gb vs. $46.5 \mathrm{~Gb})$, and 
263 to the higher published estimates for the species ( $38.9 \mathrm{~Gb}$ vs. $42.1 \mathrm{~Gb}$ ), but is much larger than

264 the average published value for this species $(\mathrm{X}=28.0 \mathrm{~Gb})$. We also estimated that $P$. idahoensis

265 has the largest genome size in the genus at $67.0 \mathrm{~Gb}$ (Sessions, 2008; Newman et al., 2016;

266 Gregory, 2021). Conversely, we estimated a significantly smaller genome size for $P$. vandykei

267 (54.6 Gb vs. $67.8 \mathrm{~Gb}$ ), which was previously considered to have the largest genome size in the

268 genus. Intraspecific variation in genome size measurements could, in principle, reflect true

269 variation within and among populations, changes in taxonomic assignments, and/or technical

270 discrepancies across studies. We circumvented these sources of uncertainty by collecting our

271 own genome size data on the same organisms we used for morphological analysis. The areas of

272 nuclei from both hepatocytes and erythrocytes are highly correlated with these genome size

273 measurements, which supports the accuracy of these data (Fig. 4; Table 1).

275 from $40.1 \mathrm{~mm}$ in $P$. cinereus to $68.7 \mathrm{~mm}$ in $P$. dunni. Mean ventricle volume spanned an order of

276 magnitude across this range of body sizes - from $0.52 \mathrm{~mm}^{3}$ in $P$. cinereus to $5.72 \mathrm{~mm}^{3}$ in $P$.

277 dunni. Mean liver volume showed a $\sim$-fold range across these body sizes, from $15.9 \mathrm{~mm}^{3}$ in $P$.

278 cinereus to $112.1 \mathrm{~mm}^{3}$ in $P$. dunni. Mean myocardial density showed a $\sim 3$-fold range across

279 species, from $0.04 \mathrm{~mm}^{2} /$ section in $P$. idahoensis to $0.118 \mathrm{~mm}^{2} /$ section in P. cinereus. The

280 mean number of vascular structures in the liver showed a $\sim 2.5$-fold range, from 23.5 / section in

$281 P$. idahoensis to 60.0 in $P$. cinereus. Mean size of vascular structures showed a $\sim 3$-fold range,

282 from $0.0021 \mathrm{~mm}^{2}$ in P. cylindraceus and P. glutinosus to $0.0061 \mathrm{~mm}^{2}$ in $P$. idahoensis. Mean

283 hepatic tissue area showed the smallest range across species, from $0.127 \mathrm{~mm}^{2}$ in $P$. glutinosus to

$2840.143 \mathrm{~mm}^{2}$ in P. idahoensis. 
286 0.001), myocardial area (Blomberg's $\mathrm{K}=0.97 ; P=0.019)$, the number of vascular structures

287 (Blomberg's $\mathrm{K}=2.69 ; P=0.002$ ), and the average size of vascular structures (Blomberg's $\mathrm{K}=$

$2882.6 ; P=0.002$ ) (Table S2). The results from the MANOVA analysis are presented in Table 3.

289 Body size (SVL) was positively correlated with ventricle size $(\mathrm{P}=0.002)$ and liver size $(\mathrm{P}<$

290 0.001; Fig. 5, Fig. S2-3). In the heart, genome size was negatively correlated with myocardial

291 area in the ventricle $(P<0.001$; Fig. 2,6$)$. In the liver, genome size showed both positive and

292 negative correlations with different traits: genome size was positively correlated with the average

293 size of the vascular structures $(\mathrm{P}<0.001$; Fig 3,6) but negatively correlated with the number of

294 vascular structures ( $\mathrm{P}<0.001$; Fig 3,6). In addition, genome size was positively correlated with

295 the total hepatic tissue area $(\mathrm{P}=0.013$; Fig. 3,6). There were also significant positive correlations

296 between body size (SVL) and the total hepatic tissue area $(\mathrm{P}=0.003)$ and the average vascular

297 structure size $(\mathrm{P}=0.006)$ in the liver.

298 Hepatic tissue area and average size of the vascular structures in the liver were

299 significantly correlated with both genome size and SVL, suggesting that these traits are

300 determined by the biological size index (BSI) - a relative measure of the total number of cells

301 comprising an organism that is based on organism size and cell size. BSI is calculated by

302 dividing the SVL by the square-root of genome size. We calculated the BSI and found that it is

303 significantly correlated with both of these traits (Fig. 7).

\section{Discussion}


308 salamanders to introduce the concept of biological size, which is a proxy for the number of cells

309 comprising an organism. We found that ventricle and liver sizes were positively correlated with

310 body size but not genome size in Plethodon salamanders, indicating that the size of these organs

311 is a function of body size (Fig. 5, S2-3). Overall, we found no relationship between genome size

312 and body size in Plethodon, indicating that increases in cell size do not produce larger body

313 sizes. Thus, the evolution of larger genome and cell size in Plethodon is accompanied by a

314 reduction in total cell numbers (i.e., reduced biological size) for both the ventricle and liver.

315 Given this result, we would predict changes in morphology because the organs now develop

316 from and consist of fewer, larger cells.

The heart and liver each showed a distinct pattern of phenotypic change accompanying

319 evolutionary increases in genome and cell size in Plethodon. In the heart, large genome and cell

320 size was accompanied by a dramatic reduction in the amount of trabeculated myocardia relative

321 to lumen space. Because ventricle size was not correlated with genome and cell size, the reduced

322 myocardial density in species with large genome sizes resulted in hearts with significantly fewer

323 myocardial cells overall.

324 In the liver, the circulatory structures were most significantly impacted by genome and

325 cell size, which resulted in distinct changes to tissue geometry. The average area of the vascular

326 structures, which included hepatic arteries, portal veins, and sinusoids, was positively correlated

327 with genome size. Conversely, the total number of these vascular structures was negatively

328 correlated with genome size. Thus, livers in species with the largest genome sizes had

329 significantly fewer, but larger, vascular structures. These results suggest that arteries, veins, and

330 liver sinusoids increase in size to accommodate larger blood cells, which in turn changes the 
331 geometry and composition of liver tissue. The changes in tissue geometry and composition

332 resulted in two dramatic alterations to overall hepatic morphology. First, the arrangement of

333 vascular structures into a portal triad-like organization was uncommon and became increasingly

334 rare as genome and cell size increased. Although the hepatic arteries, portal veins, and bile ducts

335 were present, they were rarely arranged together in a canonical portal triad. Second, the

336 hepatocytes lacked the 1-2 cell-thick, cord-like morphology, which resulted in numerous

337 hepatocytes having no direct contact with circulating blood. Akiyoshi and Inoue (2012) and

338 others described this same several-cell-thick plate morphology in salamanders (Akat and

339 Göçmen, 2014; Akat and Arkan, 2017; Vaissi et al., 2017). Our results show that this

340 morphology is a result of increased genome and cell size.

341 The patterns of phenotypic change that we report in the heart and liver, combined with

342 known patterns from brain, skeleton, and circulatory system, suggest that the impact of genome

343 and cell size increase on phenotype is organ-specific (Villalobos et al., 1988; Roth et al., 1993,

344 1994; Mueller et al., 2008). This lack of similarity suggests that, for each developing organ,

345 unique relationships exist between genome- and cell-level parameters and the morphological

346 outcome of the developmental system. Because large genome and cell size decreases the rate of

347 development, reduces the number of cells involved in morphogenesis, and/or alters the

348 composition and geometry of tissues, a full understanding of the link between cell size and

349 morphology requires understanding which of these effects is relevant for each organ.

\section{Proposed genome and cell size effects on heart development}

351 We propose three developmental hypotheses explaining the decrease in ventricular

352 musculature associated with increases in genome and cell size. First, this phenotype might arise

353 from an interaction between functional and developmental constraints derived from large cell 
354 size. Blood flow plays a significant epigenetic role in vertebrate heart development by creating

355 pressure gradients in the developing heart (Santhanakrishnan and Miller, 2011; Johnson et al.,

356 2015). Large erythrocyte size can potentially change the fluid dynamics of blood, which in turn

357 would change the degree of pressure in the heart during development. The circulation of large

358 erythrocytes has posed other functional challenges resulting in morphological evolution, evident

359 through the repeated evolution of erythrocyte enucleation in miniaturized salamander species

360 (Villalobos et al., 1988; Mueller et al., 2008; Itgen et al., 2019; Decena-Segarra et al., 2020).

361 Testing this hypothesis would require measuring blood flow, its effects on gene expression, and

362 the morphogenetic outcomes in the developing hearts of salamanders with different genome

363 sizes. Second, the reduction of ventricle muscle might be the result of slower rates of

364 development and truncation of heart organogenesis at an earlier ontogenetic stage because of

365 large genome and cell size, producing a paedomorphic heart. Third, morphogenesis and pattern

366 formation can be fundamentally changed when cell size and cell number change (Alberch and

367 Gale, 1985). Because ventricle size was not correlated with cell size, increased cell size must be

368 accompanied by decreased cell numbers. The implications of undergoing heart development with

369 fewer, larger cells are not understood. Testing the latter two hypotheses would require

370 comparative developmental analyses across taxa with different genome and cell sizes to reveal

371 how heart morphogenesis is impacted by changes in developmental rate and in the size and

372 number of cells.

\section{Proposed genome and cell size effects on liver structure}

374 The most prominent change in liver phenotype as genome and cell size increases is

375 related to tissue geometry and vasculature, which includes arteries, veins, and sinusoids. As

376 genome and cell sizes increase, the sizes of the vascular structures also increase - likely to 
377 accommodate larger blood cells — while the number of vascular structures decreases. Thus,

378 large genome and cell sizes are associated with fewer, larger vascular structures. Liver size is

379 determined by body size in Plethodon (Fig. 5), which means that increases in cell size are

380 accompanied by decreases in cell number. If the number of vascular structures were unchanged,

381 their increased size would likely cause the tissue to become functionally and/or structurally

382 compromised because they would occupy too much space, at the expense of hepatocytes.

383 Therefore, we hypothesize that the number of vascular structures is constrained to maintain

384 organ functionality and structural integrity.

The morphological changes that result from increased genome and cell size can have

391 included relative increases in brain and eye size, relative expansion of the regions of the brain

392 responsible for visual and visuomotor functions, increased cell densities within these visual

393 processing brain tissues, optic fibers, and retinas, and a proportional shift in the retina to increase

394 the number of small cones relative to the large rods (Roth et al., 1988, 1990). These

395 compensatory changes in brain and eye morphology offset the low number of large neurons

396 resulting from large cells and small body sizes, maintaining the acuity required for visual

397 predation (Roth et al., 1990).

We hypothesize that heart and liver function are affected by the evolutionary changes we

399 report in Plethodon as genome and cell size increase. In the heart, the decreased myocardial 
400 volume and increased lumen space in the ventricle likely reduce the ventricle's capacity to

401 produce force. Conversely, this reduction in myocardium allows the ventricle to hold greater

402 blood volume. A reduction of force production and increased volume capacity would alter the

403 stroke volume and ejection fraction of the heart. Overall functional measures such as heart rate

404 and cardiac output would be affected as well. In the liver, changes in hepatic tissue organization

405 likely affect function as well. Large genome and cell size impacted the organization of portal

406 triads and the cord-like morphology of hepatocytes, as well as reducing the number of vascular

407 structures. As a result, many hepatocytes do not come into direct contact with any vascular

408 structures, limiting their access to oxygen and nutrient supply and thus impacting their metabolic

409 contribution to overall organ function.

410 It is important to consider, however, whether these cell- and organ-level changes in

411 function have any effect on fitness. Variation in morphology is connected to fitness through its

412 effects on organismal performance (Arnold, 1983). Morphology can vary without impacting

413 performance, and performance, in turn, can vary without impacting fitness (Bock 1980). Are the

414 evolutionary changes that we report here in organ structure, associated with a more-than-

415 doubling of genome size, likely to impact organismal performance and fitness? We argue that the

416 changes likely have little to no effect, as a consequence of another general feature of salamander

417 physiology. Salamanders have incredibly low metabolic rates that appear unrelated to genome

418 and cell size (Gatten et al., 1992; Uyeda et al., 2017; Gardner et al., 2020; Johnson et al., 2021).

419 Low metabolic rates relax selective pressures on the functional capacity of some organs. The

420 heart, for example, is circulating blood in an organism with the lowest $\mathrm{O}_{2}$ requirements among

421 terrestrial vertebrates. The low metabolic rates of salamanders also decrease the demand for the

422 liver to metabolize macromolecules (i.e. carbohydrates, lipids, proteins) needed for oxidative 
423 phosphorylation and glycolysis. Relaxed selective pressure on organ function allows for greater

424 variation in morphology without negatively impacting organismal performance or fitness. This,

425 in turn, allows cell size to evolve driven largely by genome-level processes (e.g. transposable

426 element proliferation and deletion; Sun et al., 2012). The range of genome and cell sizes

427 produced throughout the clade's evolutionary history has been funneled through a conserved

428 developmental system, producing a range of morphologies that reflect the crossing of bifurcation

429 boundaries during organogenesis. The "permissive" organismal phenotype of salamanders is thus

430 a powerful tool for examining how the output of developmental systems responds to changes in

431 the fundamental parameter of cell size.

433 Acknowledgements: All permits were issued to M.W. Itgen and the animals were collected

434 between May and August of 2018. Plethodon idahoensis was collected from Shoshone county,

435 Idaho, under the wildlife collection permit \#180226 issued by the Idaho Department of Fish and

436 Game. Plethodon cinereus and P. glutinosus were collected from South Cherry Valley and

437 Oneonta, Otsego County, New York, under the New York State Department of Environmental

438 Conservation scientific collection permit \#2303. Plethodon vehiculum, P. vandykei, and P. dunni

439 were collected from Pacific County, Washington, under the scientific collection permit \# ITGEN

440 17-309 issued by the Washington Department of Fish and Wildlife. Plethodon metcalfi was

441 collected from Macon County, NC, and P. montanus and P. cylindraceus were collected from

442 Avery County, NC, under the wildlife collection license \# 18-SC01250 issued by the North

443 Carolina Wildlife Resources Commission. Specimens of Ambystoma mexicanum were obtained

444 from the Ambystoma Genetic Stock Center, which is funded through NIH grant: P40-

445 OD019794. We thank A. Summers, the Summers lab, and the Karel Liem Bioimaging Facility at 
446 the University of Washington's Friday Harbor Laboratories for allowing us access to their CT

447 scanner and for assistance scanning the specimens. For assistance in the field, we thank A.

448 Cicchino, A.H. Griffing, J. Hayes, M. Hayes, E. Itgen, J. Itgen, F. Rodríguez Vásquez, and S.K.

449 Sessions. For discussion of analyses and the manuscript, we thank members of MWI's

450 dissertation committee K. Hoke, D. Sloan, and W. Zhou. This research was funded by the

451 National Science Foundation (grant 1911585 awarded to RLM), the GREG R.C. Lewontin Early

452 Award awarded to MWI, the Chicago Herpetological Society Grant awarded to MWI, the

453 Stephen and Ruth Wainwright Endowment awarded to MWI, and the Helen T. and Frederick M.

454 Gaige Award awarded to MWI. Animal use was approved by the Institutional Animal Care and

455 Use Committee of Colorado State University and carried out in accordance with protocol 17-

456 7189A.

\section{References}

459 Akat, E., and B. Göçmen. 2014. A histological study of hepatic structure of Lyciasalamandra arikani (Urodela: Salamandridae). Russian Journal of Herpetology 21:201-204.

461 Akat, E. and H. Arkan. 2017. A histological study on liver of near eastern fire salamander,

464 Akiyoshi, H., and A.M. Inoue. 2012. Comparative histological study of hepatic architecture in 465 the three orders of amphibian livers. Comparative Hepatology 11:1-8.

466 Alberch, P., S.J. Gould, G.F. Oster, and D.B. Wake. 1979. Size and shape in ontogeny and 467 phylogeny. Paleobiology 5:296-317. 
Alberch P., and J. Alberch. 1981. Heterochronic mechanisms of morphological diversification and evolutionary change in the neotropical salamander, Bolitoglossa occidentalis (Amphibia: Plethodontidae). Journal of Morphology 167:249-264.

Alberch, P. 1982. Developmental constraints in evolutionary processes. Pp. 313-332 in J.T. York.

Alberch P. 1983. Morphological variation in the neotropical salamander genus Bolitoglossa. Evolution 37:906-919.

476 Alberch, P., and E. Gale. 1985. A developmental analysis of an evolutionary trend: Digital 477 reduction in amphibians. Evolution 39:8-23.

478 Arnold, S.J. 1983. Morphology, performance, and fitness. American Zoologist 23:347-361.

479 Arnold, S.J. 1992. Constraints on phenotypic evolution. American Naturalist 140:S85-S107.

480 Bock, W.J. 1980. The definition and recognition of biological adaptation. American Zoologist 20:217-227.

482 Brakefield, P.M., V. French, and B.J. Zwaan. 2003. Development and the genetics of evolutionary change within insect species. Annual Review of Ecology, Evolution, and Systematics 34:633-660.

485 Brakefield, P.M. 2006. Evo-devo and constraints on selection. Trends in Ecology \& Evolution $21: 362-368$.

487 D’Ario, M., R. Tavares, K. Schiessl, B. Desvoyes, C. Gutierrez, M. Howard, and R. Sablowski. 488 2021. Cell size controlled in plants using DNA content as an internal scale. Science 
Decena-Segarra, L.P., L. Bizjak-Mali, A. Kladnik, S.K. Sessions, and S.M. Rovito. 2020.

Miniaturization, genome size, and biological size in a diverse clade of salamanders. The American Naturalist 196:634-648.

Edgar, R.C. 2004. MUSCLE: multiple sequence alignment with high accuracy and high throughput. Nucleic Acids Research 32:1792-1797.

Elias H., and H. Bengelsdorf. 1952. The structure of the liver of vertebrates. Acta Anatomica 14: 297-337.

Fankhauser, G. 1945. The effects of changes in chromosome number on amphibian development. The Quarterly Review of Biology 20:20-78.

Fedorov, A., R. Beichel, J. Kalpathy-Cramer, J. Finet, J.C. Fillion-Robin, S. Pujol, C. Bauer, D. Jennings, F. Fennessy, M. Sonka, J. Buatti, S. Aylward, J.V. Miller, S. Pieper, and R. Kikinis. 2012. 3D Slicer as an image computing platform for the Quantitative Imaging Network. Magnetic Resonance Imaging 30:1323-1341.

Gardner, J.D., M. Laurin, and C.L. Organ. 2020. The relationship between genome size and metabolic rate in extant vertebrates. Philosophical Transactions of the Royal Society B $375,20190146$.

Gatten, R.E.J., K. Miller, and R.J. Full. 1992. Energetics at rest and during locomotion. Pp. 314377 in M.E. Feder, ed. Environmental physiology of the amphibians. University of Chicago Press, Chicago.

Gerber, S. 2014. Not all roads can be taken: development induces anisotropic accessibility in morphospace. Evolution and Development 16:373-381.

Gignac, P.M., N.J. Kley, J.A. Clarke, M.W. Colbert, A.C. Morhardt, D. Cerio, I.N. Cost, P.G. Cox, J.D. Daza, C.M. Early, M.S. Echols, R.M. Henkelman, A.N. Herdina, C.M. 

tomography (diceCT): an emerging tool for rapid, high-resolution, 3-D imaging of metazoan soft tissues. Journal of Anatomy 228:889-909.

517 Gould, S.J. 1985. Ontogeny and phylogeny. Harvard University Press, Cambridge, MA.

518 Gregory, T.R. 2001. The bigger the C-value, the larger the cell: genome size and red blood cell size in vertebrates. Blood Cells, Molecules, and Diseases 27:830-843.

520 Gregory, T.R. 2005. Genome size evolution in animals. Pp. 314-377 in T.R. Gregory, ed. The 521 Evolution of the Genome. Elsevier, San Diego, CA.

522 Gregory, T.R. 2021. Animal Genome Size Database. Available online: http://www.genomesize.com (accessed 11 July 2021).

524 Hanken, J. 1982. Appendicular skeletal morphology in minute salamanders, genus Thorius (Amphibia: Plethodontidae): growth regulation, adult size determination, and natural

527 Hanken, J. 1984. Miniaturization and its effects on cranial morphology in plethodontid salamanders, genus Thorius (Amphibia: Plethodontidae). I. Osteological variation.

530 Hanken, J., and D.B. Wake. 1993. Miniaturization of body size: organismal consequences and evolutionary significance. Annual Review of Ecology and Systematics 24:501-519.

532 Highton, R. 1995. Speciation in eastern North American salamanders of the genus Plethodon. Annual Review of Ecology and Systematics 26:579-600.

534 Humason, G.L. 1962. Animal Tissue Techniques. W. H. Freeman and Company, San Francisco, 
536 Itgen, M.W., P. Prša, R. Janža, L. Skubic, J.H. Townsend, A. Kladnik, L. Bizjak-Mali, and S.K. Sessions. 2019. Genome size diversification in Central American bolitoglossine salamanders (Caudata; Plethodontidae). Copeia 107:560-566.

539 Jaekel, M., and D.B. Wake. 2007. Developmental processes underlying the evolution of a derived foot morphology in salamanders. Proceedings of the National Academy of Sciences 104:20437-20442.

Johnson, B., D. Bark Jr., I. Van Herck, D. Garrity, and L. Prasad Dasi. 2015. Altered mechanical state in the embryonic heart results in time-dependent decreases in cardiac function. water loss, but not metabolic rate, in lungless salamanders. Journal of Experimental

548 Keyte, A.L., and K.K. Smith. 2014. Heterochrony and developmental timing mechanisms: changing ontogenies in evolution. Seminars in Cell and Developmental Biology 34:99_

551 Kumar, S., G. Stecher, and K. Tamura. 2016. MEGA7: Molecular evolutionary genetics analysis version 7.0 for bigger datasets. Molecular Biology and Evolution 33:1870-1874.

553 Lanfear, R., P.B. Frandsen, A.M. Wright, T. Senfeld, and B. Calcott. 2017. Partitionfinder 2: new methods for selecting partitioned models of evolution for molecular and morphological phylogenetic analyses. Molecular Biology and Evolution 34:772-773.

556 Lewis, Z.R., and J. Hanken. 2017. Convergent evolutionary reduction of atrial septation in 557 lungless salamanders. Journal of Anatomy 230:16-29. 
Lewontin, R.C. 1972. The Genetic Basis of Evolutionary Change. Columbia University Press, New York.

Mallarino, R., P.R. Grant, B.R. Grant, A. Herrel, W.P. Kuo, and A. Abzhanov. 2011. Two developmental modules establish 3D beak-shape variation in Darwin's finches. Proceedings of the National Academy of Science 108:4057-4062.

563 Marshall, W.F., K.D. Young, M. Swaffer, E. Wood, P. Nurse, A. Kimura, J. Frankel, J. Wallingford, V. Walbot, X. Qu, and A.H. Roeder. 2012. What determines cell size? BMC Biology 10:1-22.

Maynard Smith, J., R. Burian, S. Kauffman, P. Alberch, J. Campbell, B. Goodwin, R. Lande, D. Raup, and L. Wolpert. 1985. Developmental constraints and evolution. Quarterly Review

Mueller, R.L., T.R. Gregory, S.M. Gregory, A. Hsieh, J.L. Boore. 2008. Genome size, cell size, and the evolution of enucleated erythrocytes in attenuate salamanders. Zoology 111:218-

Mueller, R.L., C.E. Cressler, R.S. Schwarz, R.A. Chong, and M.A. Butler. 2021. Metamorphosis imposes variable constraints on genome expansion. bioRxiv

575 Newman, C.E., T.R. Gregory, and C.C. Austin. 2016. The dynamic evolutionary history of genome size in North American woodland salamanders. Genome 60:285-292.

577 Oster, G.F., and P. Alberch. 1982. Evolution and bifurcation of developmental programs.

578 Evolution 36:444-462.

579 Oster, G., N. Shubin, J.D. Murray, and P. Alberch. 1988. Evolution and morphogenetic rules.

580 The shape of the vertebrate limb in ontogeny and phylogeny. Evolution 42:862-884. 
581 Powder, K.E., K. Milch, G. Asselin, and R.C. Albertson. 2015. Constraint and diversification of developmental trajectories in cichlid facial morphologies. EvoDevo 6, https://doi.org/10.1186/s13227-015-0020-8.

584 R Core Team. 2016. R: a language and environment for statistical computing. R Foundation for Statistical Computing, Vienna, Austria. http://www.R-project.org/

Revell, L.J. 2012. Phytools: an R package for phylogenetic comparative biology (and other things). Methods in Ecology and Evolution 3:217-223.

Ronquist, F., M. Teslenko, P. van der Mark, D.L. Ayres, A. Darling, S. Höhna, B. Larget, L. Liu, M.A. Suchard, and J.P. Huelsenbeck. (2012). MrBayes 3.2: efficient Bayesian phylogenetic inference and model choice across a large model space. Systematic Biology. 61:539-542.

Roth, G., B. Rottluff, and R. Linke. 1988. Miniaturization, genome size and the origin of functional constraints in the visual system of salamanders. Naturwissenschaften 75:297-

Roth, G., B. Rottluff, W. Grunwald, J. Hanken, and R. Linke. 1990. Miniaturization in plethodontid salamanders (Caudata: Plethodontidae) and its consequences for the brain and visual system. Biological Journal of the Linnean Society 40:165-190.

598 Roth, G., K.C. Nishikawa, C. Naujoks-Manteuffel, A. Schmidt, and D.B. Wake. 1993. Paedomorphosis and simplification in the nervous system of salamanders. Brain, Behavior, and Evolution 42:137-170.

601 Roth, G., J. Blanke, and D. B. Wake. 1994. Cell size predicts morphological complexity in the brains of frogs and salamanders. Proceedings of the National Academy of Sciences of the United States of America 91:4796-4800. 
604 Roth, G., and W. Walkowiak. 2015. The influence of genome and cell size on brain morphology

605 in amphibians. Cold Spring Harbor Perspectives in Biology 7, a019075.

606 Salazar-Ciudad, I. 2006. Developmental constraints vs. variation properties: how pattern

607 formation can help to understand evolution and development. Journal of Experimental

608 Zoology Part B: Molecular and Developmental Evolution 306:107-125.

609 Santhanakrishnan, A., and L.A. Miller. 2011. Fluid dynamics of heart development. Cell

$610 \quad$ biochemistry and biophysics 61:1-22.

611 Schmidt, A., and G. Roth. 1993. Patterns of cellular proliferation and migration in the developing

612 tectum mesencephali of the frog Rana temporaria and the salamander Pleurodeles waltl.

613 Cell and Tissue Research 272:273-287.

614 Schneider, C.A., W.S. Rasband, and K.W. Eliceiri. 2012. NIH Image to ImageJ: 25 years of 615 image analysis. Nature Methods 9:671-675.

616 Sessions, S.K., and A. Larson. 1987. Developmental correlates of genome size in plethodontid

617 salamanders and their implications for genome evolution. Evolution 41:1239-1251.

618 Sessions, S.K. 2008. Evolutionary cytogenetics in salamanders. Chromosome Research 16:183-

619201.

620 Sessions, S.K., and D.B. Wake. 2021. Forever young: linking regeneration and genome size in $621 \quad$ salamanders. Developmental Dynamics 250:768-778.

622 Snyder, G.K., and B.A. Sheafor. 1999. Red blood cells: centerpiece in the evolution of vertebrate circulatory system. American Zoologist 39:189-198.

624 Stephenson, A., J.W. Adams, and M. Vaccarezza. 2017. The vertebrate heart: an evolutionary 625 perspective. Journal of Anatomy 231:787-797. 
626 Sun, C., D.B. Shepard, R.A. Chong, J.L. Arriaza, K. Hall, TA. Castoe, C. Feschotte, D.D. Pollock, and R.L. Mueller. 2012. LTR retrotransposons contribute to genomic gigantism in plethodontid salamanders. Genome Biology and Evolution 4:168-183.

629 Uller, T., A.P. Moczek, R.A. Watson, P.M. Brakefield, and K.N. Laland. 2018. Developmental bias and evolution: a regulatory network perspective. Genetics 209:949-966.

631 Uyeda, J.C., M.W. Pennell, E.T. Miller, R. Maia, and C.R. McClain. 2017. The evolution of energetic scaling across the vertebrate tree of life. The American Naturalist 190:185-199.

633 Vaissi, S., P. Parto, and M. Sharifi. 2017. Anatomical and histological study of the liver and pancreas of two closely related mountain newts: Neurergus microspilotus and N. kaiseri (Amphibia: Caudata: Salamandridae). Zoologia 34:1-8.

636 Vinogradov, A.E. 1999. Genome in toto. Genome 42:361-362.

637 Villalobos, M., P. León, S.K. Sessions, and J. Kezer. 1988. Enucleated erythrocytes in plethodontid salamanders. Herpetologica 44:243-250.

639 Wagner, A. 2011. Genotype networks shed light on evolutionary constraints. Trends in Ecology and Evolution 26:577-584.

641 Wake D.B. 1966. Comparative osteology and evolution of the lungless salamanders, family Plethodontidae. Southern California Academy of Sciences 4:1-111.

643 Wake, D.B. 1991. Homoplasy: the result of natural selection or evidence of design limitations? Am. Nat. 138:543-567.

645 Womack, M.C., M.J. Metz, and K.L. Hoke. 2019. Larger genomes linked to slower development 646 and loss of late-developing traits. The American Naturalist 194:854-864. 
648 Table 1. Mean and standard deviation for measurements of genome size, nuclear areas of

649 erythrocytes and hepatocytes, and cell areas of hepatocytes. $n=5$ individuals unless otherwise

650 noted; 3-5 erythrocyte nuclei and 20 hepatic nuclei and cells were measured per individual.

\begin{tabular}{|c|c|c|c|c|}
\hline Species & $\begin{array}{l}\text { Genome } \\
\text { size }(\mathrm{Gb})\end{array}$ & $\begin{array}{l}\text { Nuclear area of erythrocytes } \\
\qquad\left(\mathrm{um}^{2}\right)\end{array}$ & $\begin{array}{c}\text { Nuclear area of } \\
\text { hepatocytes }\left(\mathrm{um}^{2}\right)\end{array}$ & $\begin{array}{c}\text { Cell area of hepatocytes } \\
\left(\mathrm{um}^{2}\right)\end{array}$ \\
\hline P. cinereus & $\begin{array}{c}29.3 \pm 1.34 \\
(\mathrm{n}=4)\end{array}$ & $54.5 \pm 3.6$ & $84.2 \pm 3.7$ & $373.8 \pm 59.5$ \\
\hline P. montanus & $36.0 \pm 3.4$ & $58.7 \pm 5.1$ & $92.5 \pm 4.6$ & $515.3 \pm 34.8$ \\
\hline P. cylindraceus & $37.1 \pm 5.4$ & $66.9 \pm 10.4$ & $92.2 \pm 3.9$ & $550.4 \pm 27.2$ \\
\hline P. metcalfi & $38.3 \pm 1.04$ & $58.5 \pm 2$ & $87.7 \pm 3.8$ & $492.7 \pm 90.3$ \\
\hline P. glutinosus & $38.9 \pm 3.94$ & $62.5 \pm 6.2$ & $97.8 \pm 6.4$ & $498.6 \pm 42.9$ \\
\hline P. vehiculum & $\begin{array}{c}46.4 \pm 7.08 \\
(n=3)\end{array}$ & $86.4 \pm 17.6$ & $128.8 \pm 5.6$ & $740.1 \pm 71.4$ \\
\hline P. dunni & $52.3 \pm 4.06$ & $88.2 \pm 5.7$ & $137.1 \pm 6.2$ & $755.2 \pm 108.6$ \\
\hline P. vandykei & $\begin{array}{c}54.6 \pm 2.2 \\
(\mathrm{n}=4)\end{array}$ & $104.3 \pm 20.4$ & $158.4 \pm 9.8$ & $943 \pm 227.5$ \\
\hline P. idahoensis & $67.0 \pm 2.31$ & $116.9 \pm 2.9$ & $181.7 \pm 8$ & $984.5 \pm 371$ \\
\hline
\end{tabular}

651

652 Table 2. Mean and standard deviation for genome size and morphological traits. $\mathrm{n}=5$

653 individuals unless otherwise noted; 5 slides were measured per individual.

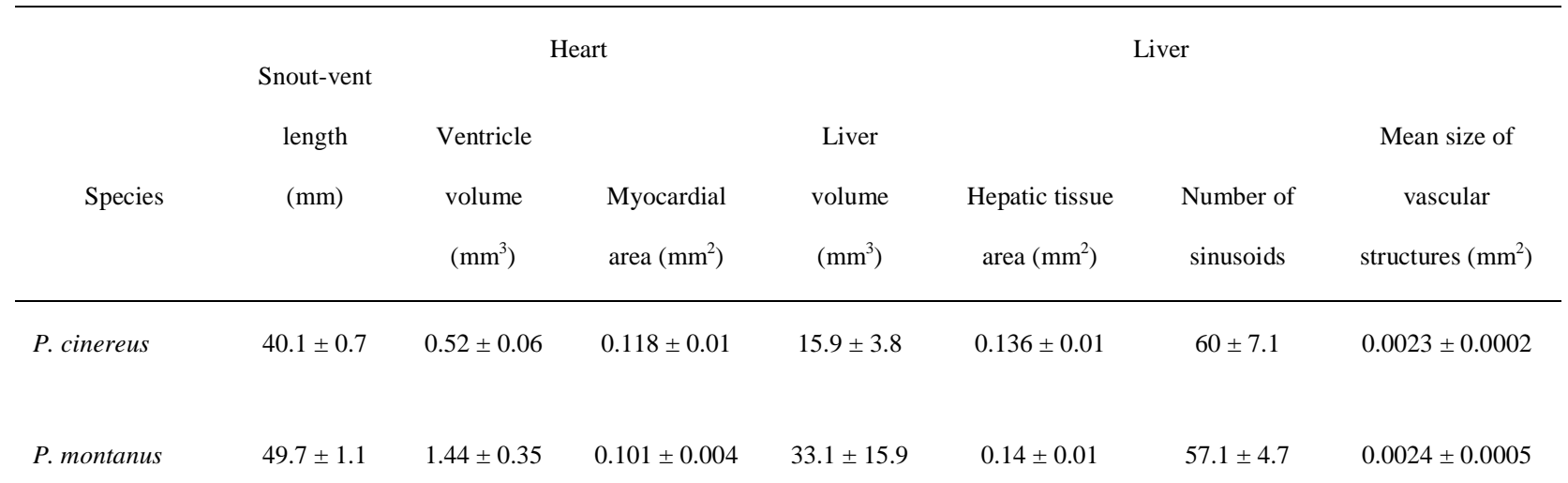




\begin{tabular}{|c|c|c|c|c|c|c|c|}
\hline P. cylindraceus & $70.4 \pm 1.6$ & $3.77 \pm 1.24$ & $0.107 \pm 0.01$ & $120 \pm 72.5$ & $0.123 \pm 0.01$ & $58.4 \pm 8.8$ & $0.0021 \pm 0.0002$ \\
\hline P. metcalfi & $61.9 \pm 4.2$ & $3.74 \pm 1.63$ & $0.106 \pm 0.004$ & $70.6 \pm 41.3$ & $0.136 \pm 0.01$ & $54.7 \pm 6.6$ & $0.0025 \pm 0.0002$ \\
\hline P. glutinosus & $66.9 \pm 2.4$ & $3.71 \pm 1.63$ & $\begin{array}{c}0.101 \pm 0.002 \\
(n=4)\end{array}$ & $77.9 \pm 40.3$ & $0.127 \pm 0.01$ & $59.6 \pm 3.5$ & $0.0021 \pm 0.0002$ \\
\hline P. vehiculum & $50.5 \pm 0.7$ & $0.9 \pm 0.1$ & $0.09 \pm 0.004$ & $40 \pm 5.6$ & $0.141 \pm 0.003$ & $34.4 \pm 3.0$ & $0.0041 \pm 0.0005$ \\
\hline P. dunni & $68.7 \pm 1.2$ & $5.72 \pm 1.59$ & $0.065 \pm 0.01$ & $\begin{array}{c}112.1 \pm 63.1 \\
(n=3)\end{array}$ & $0.136 \pm 0.004$ & $32.4 \pm 4.9$ & $0.0042 \pm 0.0002$ \\
\hline P. vandykei & $54.2 \pm 2.0$ & $1.51 \pm 0.42$ & $0.073 \pm 0.01$ & $\begin{array}{c}62.2 \pm 17.9 \\
(n=4)\end{array}$ & $0.142 \pm 0.002$ & $26.3 \pm 4.8$ & $0.0054 \pm 0.0006$ \\
\hline P. idahoensis & $58.1 \pm 2.1$ & $2.63 \pm 0.78$ & $0.043 \pm 0.01$ & $\begin{array}{c}40.1 \pm 14.7 \\
(n=4)\end{array}$ & $0.143 \pm 0.004$ & $23.5 \pm 3.0$ & $0.0061 \pm 0.0002$ \\
\hline
\end{tabular}

655 Table 3. Results from the univariate ANOVA showing the individual interactions between the

656 predictor and response variables.

$\begin{array}{llll}\text { Predictor variable } & \text { Response variable } & \text { F } & P\end{array}$

Genome size $(\mathrm{Gb})$

Liver volume $\left(\mathrm{mm}^{3}\right)$

0.2

0.658

Hepatic tissue area $\left(\mathrm{mm}^{2}\right)$

12.2

0.013

Average vascular structure size $\left(\mathrm{mm}^{2}\right)$

215.8

$<0.001$

Number of vascular structures

55.8

$<0.001$

Ventricle volume $\left(\mathrm{mm}^{3}\right)$

1.2

0.31

Myocardial area $\left(\mathrm{mm}^{2}\right)$

173.9

$<0.001$

Snout-vent length (mm)

Liver volume $\left(\mathrm{mm}^{3}\right)$

Hepatic tissue area $\left(\mathrm{mm}^{2}\right)$ 

Number of vascular structures
2.4
0.173557
Ventricle volume $\left(\mathrm{mm}^{3}\right)$
18.5
0.002658
Myocardial area $\left(\mathrm{mm}^{2}\right)$
0.02
0.895659

660

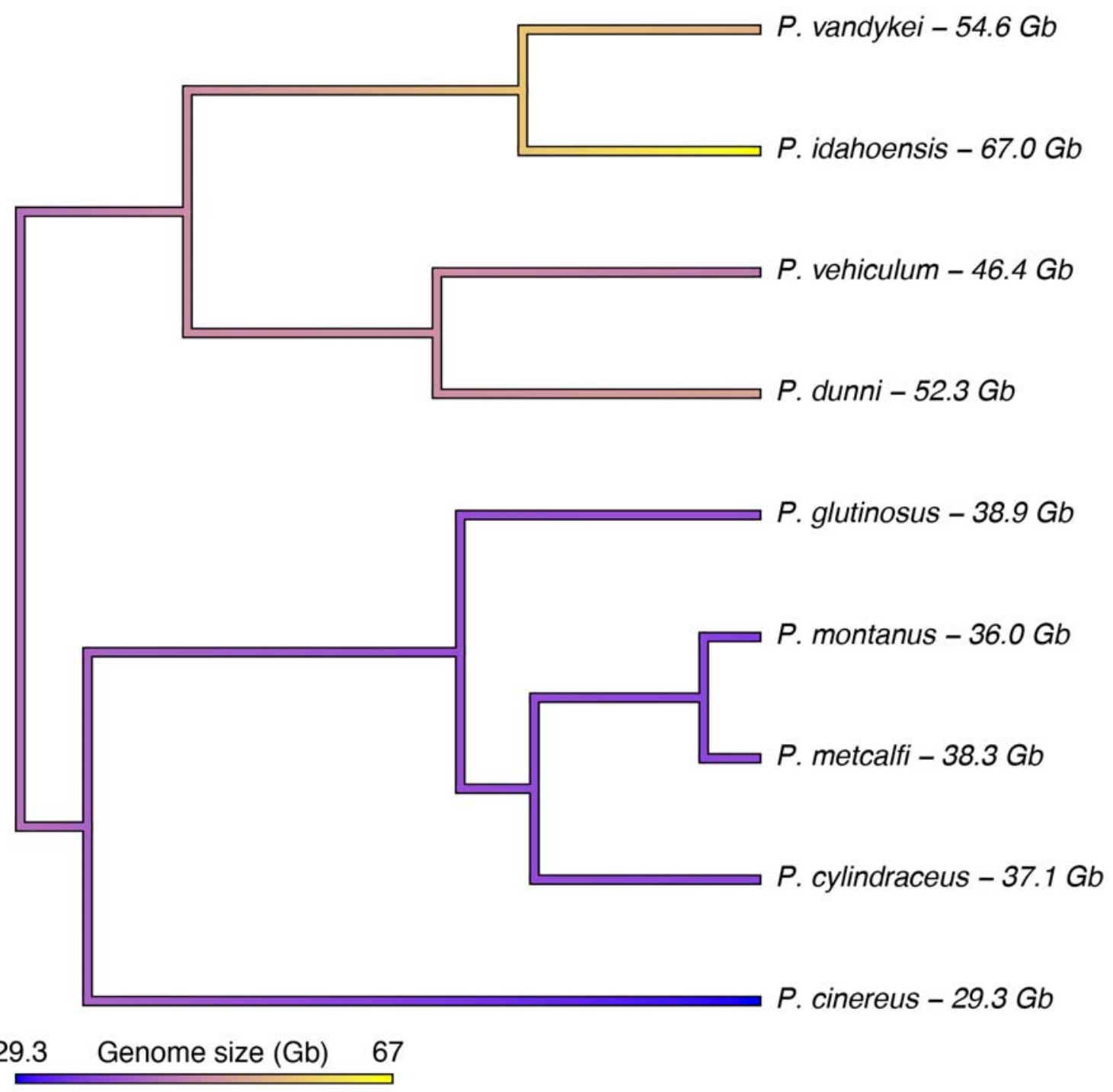

662 Figure 1. Genome size mapped as a continuous trait onto the topology for the 9 species of

663 Plethodon to visualize differences among species. 


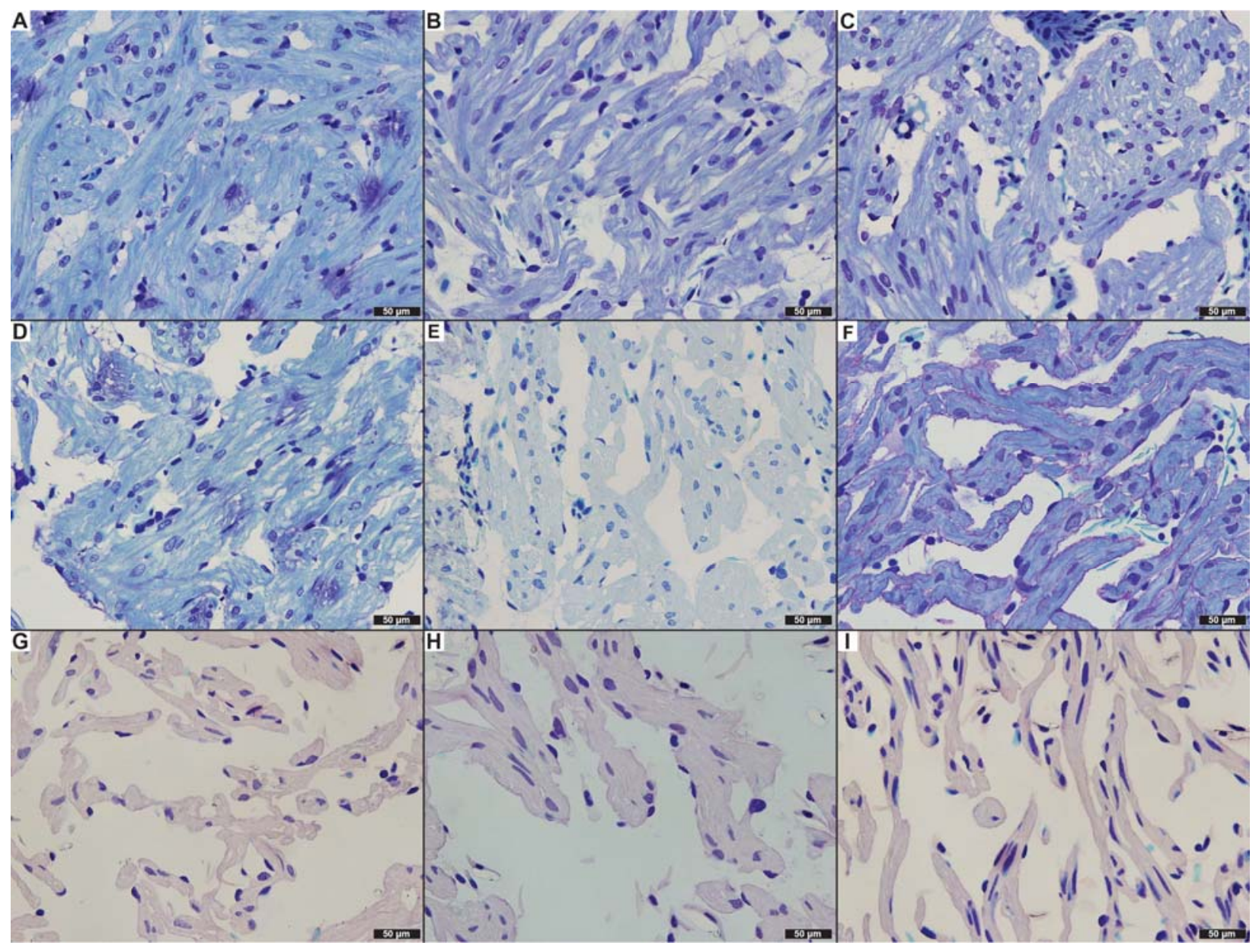

666 Figure 2. Histological sections of the ventricle at 20x magnification for each species arranged by

667 increasing genome size. A) P. cinereus, $29.3 \mathrm{~Gb}$; B) P. montanus, $36 \mathrm{~Gb}$; C) P. cylindraceus,

668 37.1 Gb; D) P. metcalfi, $38.3 \mathrm{~Gb}$; E) P. glutinosus, $38.9 \mathrm{~Gb}$; F) P. vehiculum, $46.4 \mathrm{~Gb}$; G) P.

669 dunni, $52.3 \mathrm{~Gb}$; H) P. vandykei, $54.6 \mathrm{~Gb}$; I) P. idahoensis, $67 \mathrm{~Gb}$. 


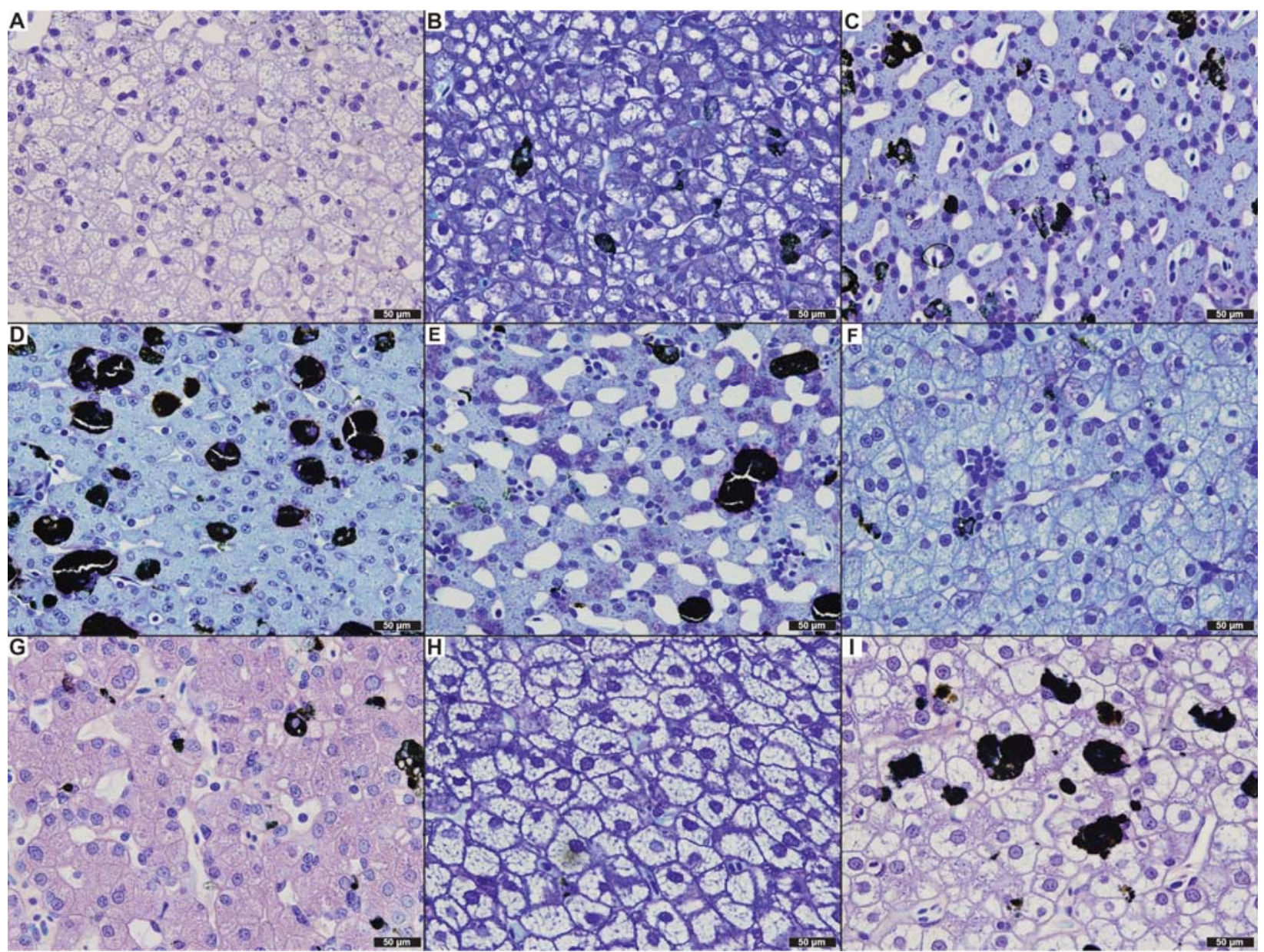

672 Figure 3. Histological sections of the liver at 20x magnification for each species arranged by

673 increasing genome size. A) P. cinereus, $29.3 \mathrm{~Gb}$; B) P. montanus, $36 \mathrm{~Gb}$; C) P. cylindraceus,

$67437.1 \mathrm{~Gb}$; D) P. metcalfi, $38.3 \mathrm{~Gb}$; E) P. glutinosus, $38.9 \mathrm{~Gb}$; F) P. vehiculum, $46.4 \mathrm{~Gb}$; G) P.

675 dunni, $52.3 \mathrm{~Gb}$; H) P. vandykei, $54.6 \mathrm{~Gb}$; I) P. idahoensis, $67 \mathrm{~Gb}$. 
A)

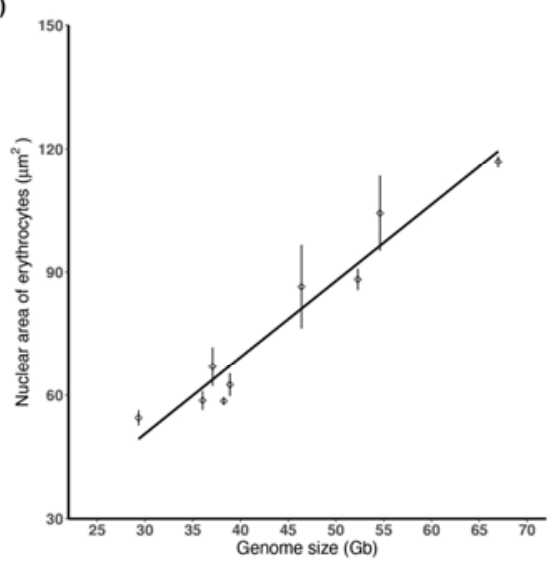

B)

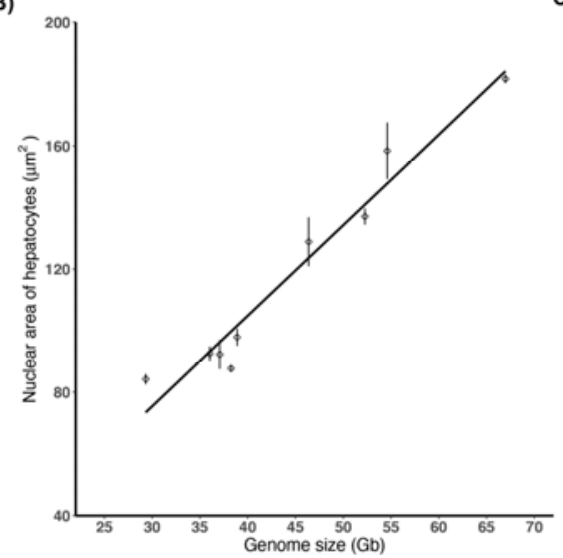

C)

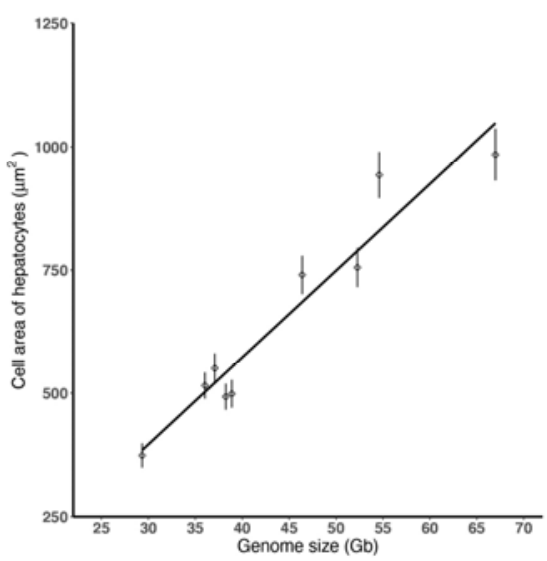

678 Figure 4. Genome size has a strong positive correlation with the A) nuclear area of erythrocytes,

679 B) nuclear area of hepatocytes, and C) cell area of hepatocytes across the nine species. Error bars

680 represent standard error.

681

A)

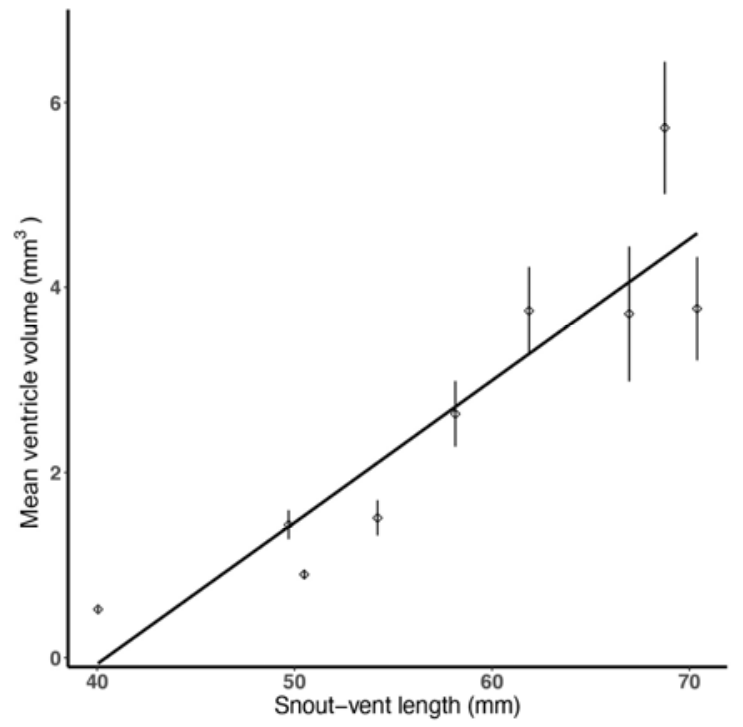

B)

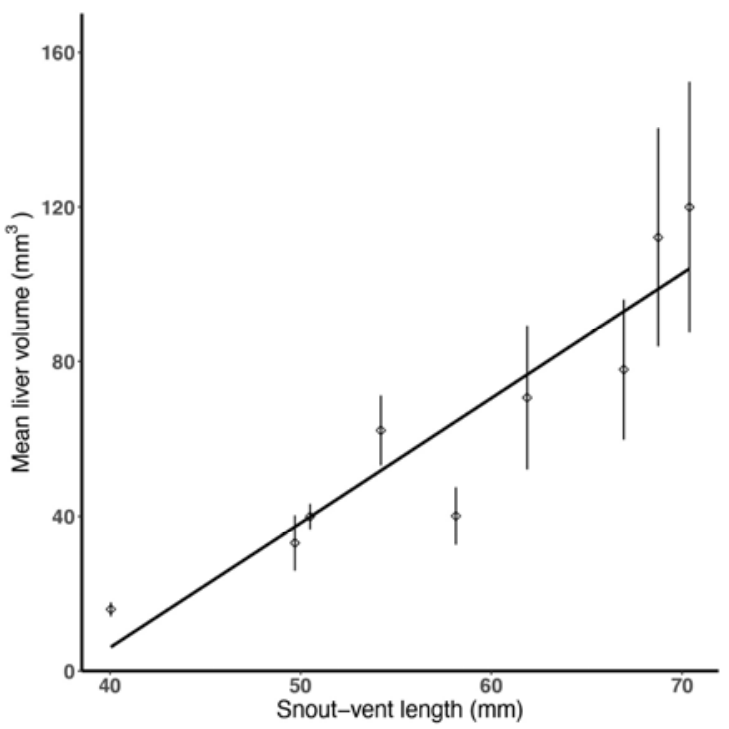

683 Figure 5. Body size (SVL) is positively correlated with A) ventricle size and B) liver size. Error bars represent standard error. 
A)

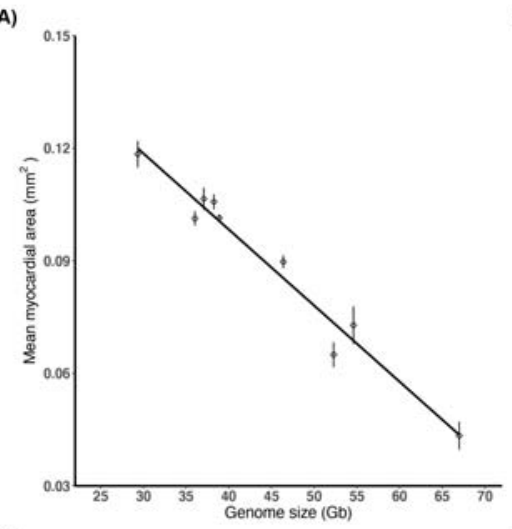

C)

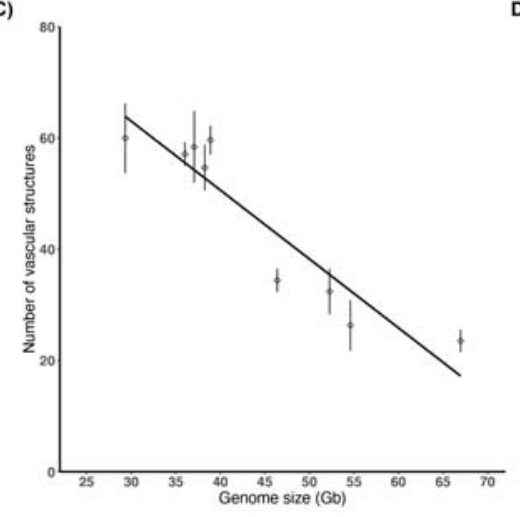

B)

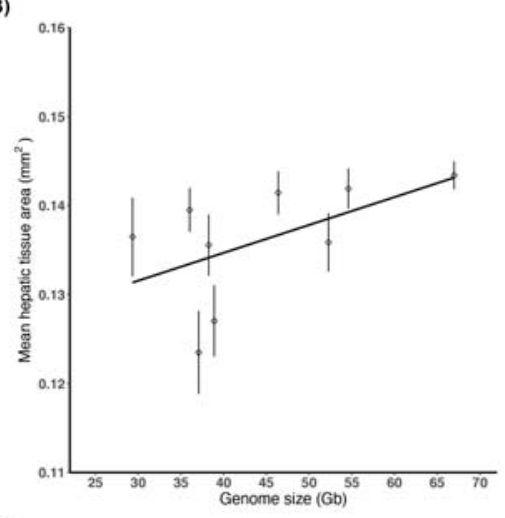

D)

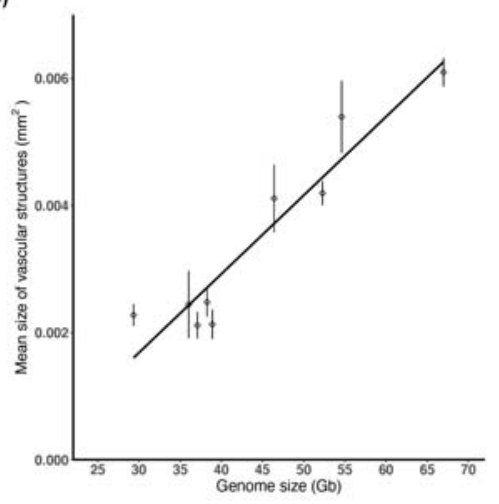

687 Figure 6. An increase in genome size is correlated with A) a decrease in myocardial area, B) an

688 increase in hepatic tissue area, C) a decrease in the number of vascular structures, and D) an

689 increase the size of vascular structures. Error bars represent standard error.

690

A)

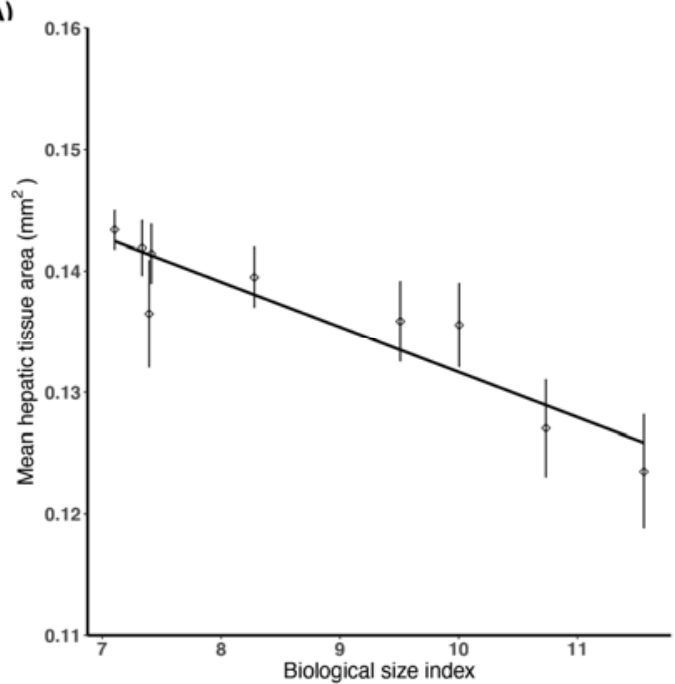

B)

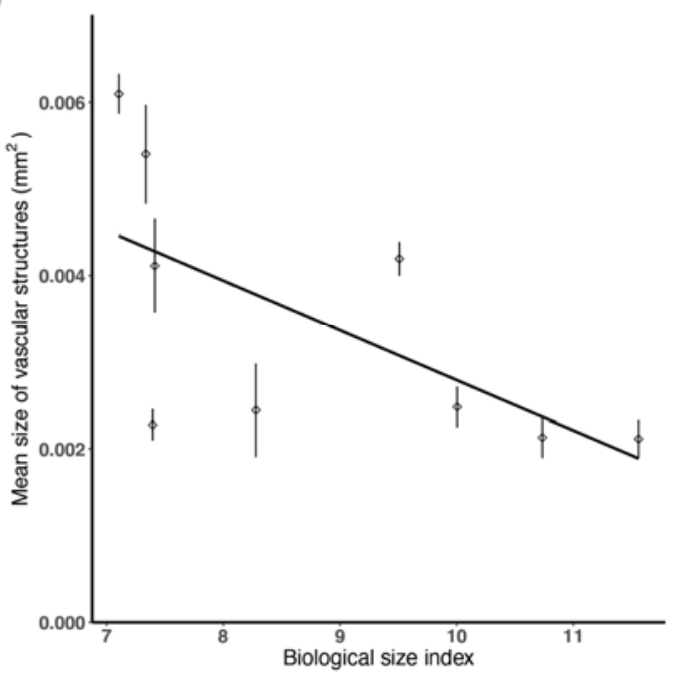


692 Figure 7. An increase in biological size index (SVL / $\sqrt{ }$ genome size) is correlated with A) a

693 decrease in hepatic tissue area and B) a decrease in the size of vascular structures. Error bars

694 represent standard error.

695

696 Table S1. GenBank accession numbers for sequences used in the phylogenetic analysis.

\begin{tabular}{lll}
\hline & \multicolumn{2}{l}{ GenBank Accession Numbers } \\
\cline { 2 - 3 } Species & Ratb & \\
\hline Plethodon cinereus & AY691745 & JF449378 \\
$P$. cylindraceus & DQ994929 & DQ995022 \\
$P$. dunni & AY183763 & KF911900 \\
$P$. glutinosus & DQ994936 & DQ995027 \\
$P$. idahoensis & AY572107 & DQ995031 \\
$P$. metcalfi & DQ994957 & DQ995040 \\
$P$. montanus & DQ994962 & DQ995043 \\
$P$. vandykei & AY572045 & AY691715 \\
$P$. vehiculum & JF521651 & AY691716 \\
\hline
\end{tabular}

697

698 Table S2. Estimates of phylogenetic signal for each trait used in the MANOVA analysis using

699 Blomberg's K. Traits with significant estimates of phylogenetic signal are in bold.

Measure of Phylogenetic Signal

\section{Traits}

Snout-vent length (mm)

Genome size (Gb)

Liver volume $\left(\mathrm{mm}^{3}\right)$

\section{Blomberg's K}

0.37

0.375

1.51

0.001

0.357

0.45 
Ventricle volume $\left(\mathrm{mm}^{3}\right)$

Myocardial area $\left(\mathrm{mm}^{2}\right)$

Hepatic tissue area $\left(\mathrm{mm}^{2}\right)$

Number of vascular structures

Average vascular structure size $\left(\mathrm{mm}^{2}\right)$
0.348

0.97

0.564

2.69

2.6

0.002

700

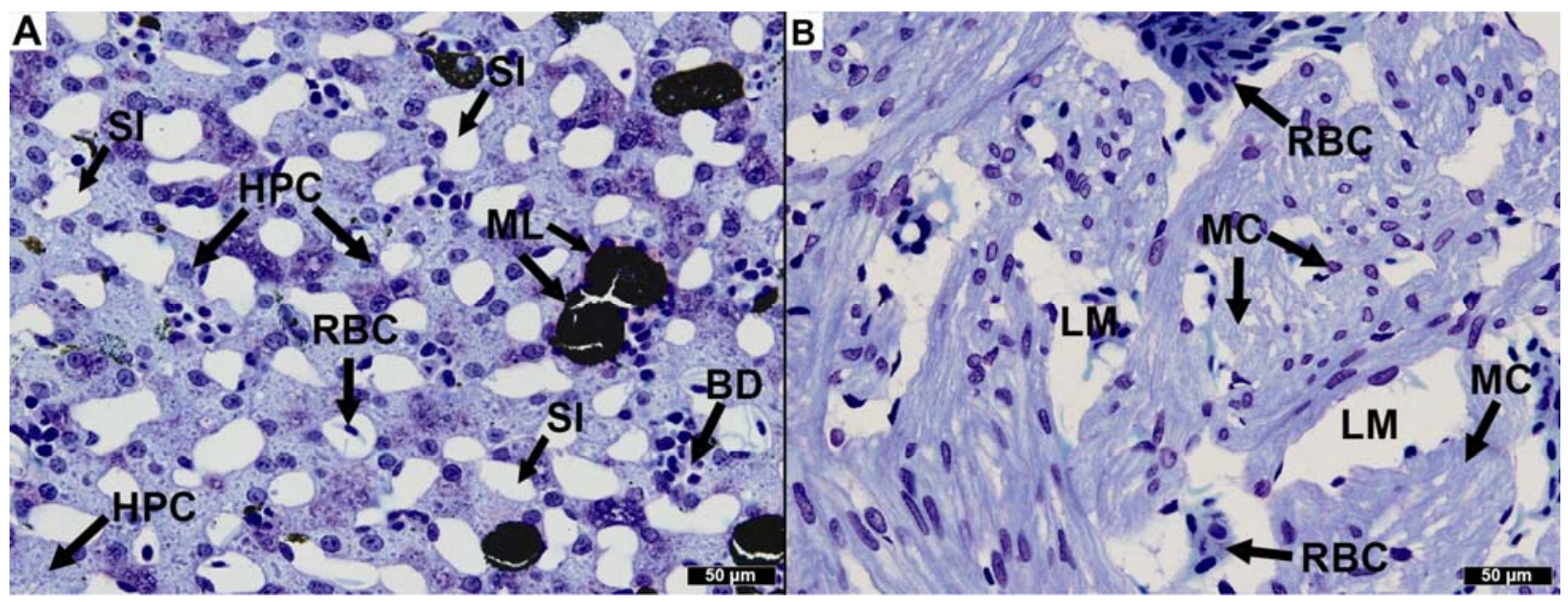

702 Figure S1. A) Histological section of liver tissue identifying bile ducts (BD), hepatocytes (HPC),

703 melanocytes (ML), red blood cells (RBC), and sinusoids (SI). B) Histological section of the

704 ventricle identifying the lumen (LM), myocardium (MC), and red blood cells (RBC). 


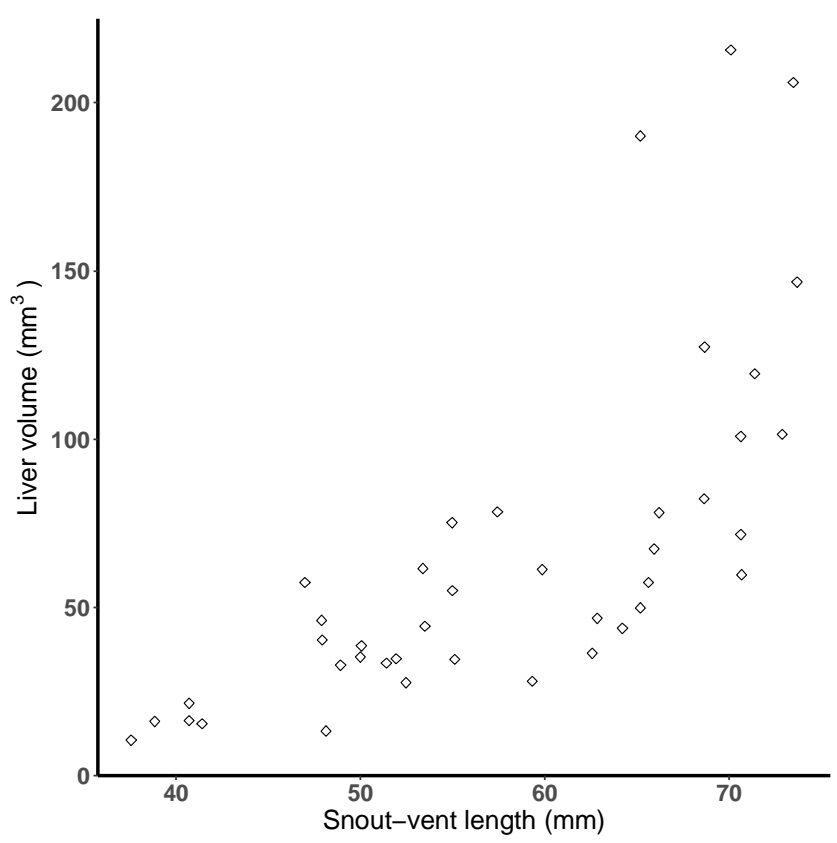

707 Figure S2. Relationship between liver volume $\left(\mathrm{mm}^{3}\right)$ and SVL ( $\left.\mathrm{mm}\right)$ for each individual across

708 all species.

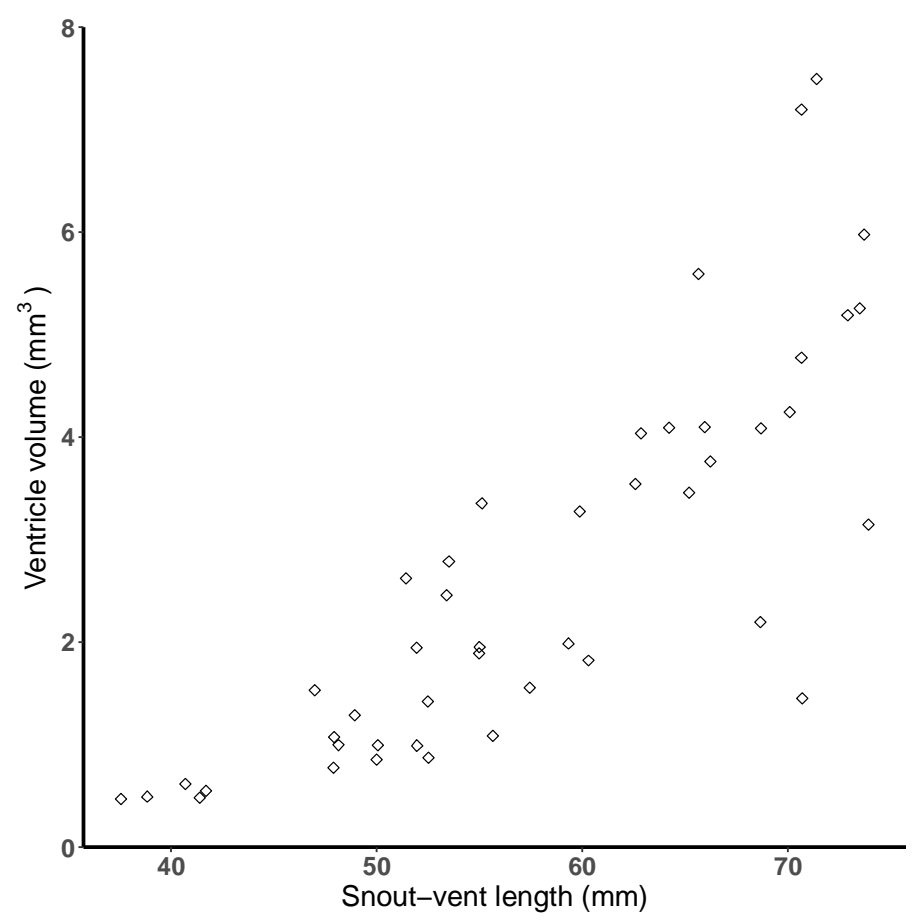

710 Figure S3. Relationship between ventricle volume $\left(\mathrm{mm}^{3}\right)$ and SVL $(\mathrm{mm})$ for each individual

711 across all species. 